\title{
Effect of a high-fat diet on the hepatic expression of nuclear receptors and their target genes: relevance to drug disposition
}

\author{
Ragia H. Ghoneim ${ }^{1}$, Emilienne T. Ngo Sock ${ }^{2}$, Jean-Marc Lavoie ${ }^{2}$ and Micheline Piquette-Miller ${ }^{1 *}$ \\ ${ }^{1}$ Department of Pharmaceutical Sciences, Leslie Dan Faculty of Pharmacy, University of Toronto, Toronto, ON, \\ Canada M5S $3 M 2$ \\ ${ }^{2}$ Department of Kinesiology, University of Montreal, QC, Canada \\ (Submitted 15 May 2014 - Final revision received 30 July 2014 - Accepted 21 October 2014 - First published online 23 January 2015)
}

\section{Abstract}

More than 1.4 billion individuals are overweight or obese worldwide. While complications often require therapeutic intervention, data regarding the impact of obesity on drug disposition are scarce. As the influence of diet-induced obesity on drug transport and metabolic pathways is currently unclear, the objective of the present study was to investigate the effect of high fat feeding for 13 weeks in female Sprague-Dawley rats on the hepatic expression of the nuclear receptors pregnane X receptor $(P X R)$, constitutive androstane receptor $(C A R)$, liver $\mathrm{X}$ receptor $(L X R)$ and farnesoid $\mathrm{X}$ receptor $(F X R)$ and several of their target genes. We hypothesised that high fat feeding would alter the gene expression of major hepatic transporters through a dysregulation of the expression of the nuclear receptors. The results demonstrated that, along with a significant increase in body fat and weight, a high-fat diet (HFD) induced a significant 2-fold increase in the expression of $P X R$ as well as a 2-, 5- and 2.5-fold increase in the hepatic expression of the $P X R$ target genes $A b c c 2, A b c b 1 a$ and $C y p 3 a 2$, respectively $(P<0.05)$. The expression levels of $F X R$ were significantly increased in rats fed a HFD in addition to the increase in the expression levels of FXR target genes $A b c b 11$ and $A b c b 4$. The expression levels of both $L X R \alpha$ and $L X R \beta$ were slightly but significantly increased in rats fed a HFD, and the expression levels of their target genes $A b c a 1$ and $A b c g 5$, but not $A b c g 8$, were significantly increased. The expression of the nuclear receptor $C A R$ was not significantly altered between the groups. This suggests that a HFD may induce changes in the hepatobiliary transport and metabolism of endogenous and exogenous compounds.

\section{Key words: Drug transporters: Obesity: Pregnane $\mathbf{X}$ receptor: Farnesoid X receptor: P-glycoprotein}

Obesity affects more than 500 million individuals and is currently the fifth leading risk of death worldwide ${ }^{(1)}$. The clinical importance of this disease stems from its associated complications including liver diseases, metabolic diseases, cardiovascular disease, gastrointestinal problems and musculoskeletal disorders ${ }^{(2-6)}$. Therefore, overweight and obese patients are on numerous medications, many of which are cleared through hepatobiliary mechanisms. However, it is plausible that obesity and its related complications may alter the hepatobiliary clearance of endogenous and exogenous compounds. There is a scarcity of information regarding the effect of obesity on hepatic transport and/or metabolic pathways. Previous studies have reported obesity-related alterations in the pharmacokinetics of clinically important drugs such as verapamil, vancomycin and $\beta$-lactam antibiotics ${ }^{(7)}$, and studies have indicated that anti-retroviral drugs may be less effective in obese patients ${ }^{(8)}$. This could be attributed to alterations in the distribution, metabolism and/or transport of the drug. Indeed, increased cytochrome P450 2E1 (CYP2E1) activity leading to the increased clearance of chlorzoxazone has been reported in obese patients ${ }^{(9)}$. Studies in genetic rodent models of obesity have reported altered expression of hepatic drug transporters and metabolic enzymes ${ }^{(10-13)}$. Studies in human subjects, as well as in diet-induced obesity rodent models, have shown that obesity, insulin resistance and type 2 diabetes are associated with a tendency towards increased cholesterol synthesis and decreased absorption, which is associated with an increase in the expression of the cholesterol efflux

Abbreviations: $A b c g 5$, ATP-binding cassette subfamily G member 5; $A b c g 8$, ATP-binding cassette subfamily G member 8; $A b c b 4$, ATP-binding cassette subfamily B member 4; Abcb11, ATP-binding cassette subfamily B member 11; Abcc2, ATP-binding cassette subfamily C member 2; CAR, constitutive androstane receptor; Cyp7a1, cytochrome P450 7A1; Cyp3a2, cytochrome P450 3A2; FXR, farnesoid X receptor; HFD, high-fat diet; LXR $\alpha$, liver X receptor- $\alpha$; LXR $\beta$, liver X receptor- $\beta$; MRP, multi-drug resistance-associated proteins; Pgp, P-glycoprotein; PXR, pregnane X receptor; SD, standard diet.

*Corresponding author: Professor Dr M. Piquette-Miller, fax +1 416978 8511, email m.piquette.miller@utoronto.ca 
transporters $A b c g 5 / A b c g 58$ (ATP-binding cassette subfamily G member 5/8) and Abca1 (ATP-binding cassette subfamily A member 1$)^{(14-17)}$.

In addition to genetic factors, an imbalance between energy intake and expenditure highly contributes to the development of obesity. In particular, the intake of high-fat diets (HFD) seems to be a principal factor ${ }^{(18)}$. Several models of dietinduced obesity using a HFD have been developed in rodents $^{(19)}$. Besides increased weight gain, high fat feeding results in a surplus of fatty acids, which contributes to hepatic lipogenesis in the form of triglycerides (TAG). It is believed that the liver has a limited capacity to store excess TAG, after which steatosis accompanied by cell damage occurs ${ }^{(20)}$. Several inflammatory mediators released during hepatocellular damage, particularly IL- 6 and TNF- $\alpha$, seem to act as key players $^{(21)}$, and have previously been shown to regulate drug disposition pathways. One of the mechanisms by which this may occur is through alterations in the expression and translocation of nuclear receptor proteins ${ }^{(22)}$.

Many nuclear receptors act as key transcriptional regulators of genes that are involved in transport, metabolism and detoxification pathways (Table 1$)^{(22)}$. Pregnane $\mathrm{X}$ receptor (PXR/NR1I2 (nuclear receptor subfamily 1, group I, member 2)), which serves as the main xenobiotic sensor, regulates the expression of the most abundantly expressed microsomal enzyme, CYP3A4 (cytochrome P450 3A4; Cyp3a2 (cytochrome $\mathrm{P} 450$ 3A2) in rats) ${ }^{(23)}$, as well as a plethora of drug transporters including key members of the ABC family such as P-glycoprotein (Pgp) (ABCB1, ATP-binding cassette subfamily $\mathrm{B}$ member 1) and the multi-drug resistance-associated proteins (ABCC, ATP-binding cassette subfamily C). The constitutive androstane receptor (CAR/NR1I3 (nuclear receptor subfamily 1 , group I, member 3)) is another xenobiotic-sensing nuclear receptor, which regulates drug detoxification pathways through the induction of an overlapping set of genes, including Pgp, $A B C C 2, A B C C 3$ and $C Y P 2 B 6$ (cytochrome $\mathrm{P} 450$ 2B6) ${ }^{(23)}$.

Liver $\mathrm{X}$ receptor $(\mathrm{LXR} \alpha / \beta / \mathrm{NR} 1 \mathrm{H} 3 / 2$ (nuclear receptor subfamily 1 , group $H$, member $3 / 2$ )) is a main regulator of cholesterol metabolism, and has recently been shown to play a role in the pathogenesis of inflammation ${ }^{(24)}$. Oxysterols, the oxygenated derivatives of cholesterol, activate LXR, thereby promoting the clearance of cholesterol through the induction of several transporters including ABCA1, ABCG1 (ATP-binding cassette subfamily G member 1), ABCG5/ABCG8 as well as the sterol regulatory element-binding protein 1 that promotes TAG synthesis ${ }^{(25)}$. In rodents, LXR also induces cytochrome P450 7A1 (Cyp7a1), which metabolises cholesterol to bile

Table 1. Nuclear receptors and their target genes

\begin{tabular}{|c|c|c|}
\hline Nuclear receptors & Target genes & References \\
\hline \multirow[t]{8}{*}{ PXR (NR1I2) } & $A b c b 1$ & Urquhart et al. ${ }^{(23)}$, Anger \& Piquette-Miller ${ }^{(43)}$, Chen et al ${ }^{(55)}$, Geick et al..$^{(56)}$, Tirona \& Kim ${ }^{(57)}$ \\
\hline & $A b c c 2$ & Urquhart et al. ${ }^{(23)}$, Anger \& Piquette-Miller ${ }^{(43)}$, Kast et al. ${ }^{(50)}$, Chen et al..$^{(55)}$ \\
\hline & Abcc3 & Anger \& Piquette-Miller ${ }^{(43)}$ Tirona \& $\mathrm{Kim}^{(57)}$ \\
\hline & $A b c g 2$ & Chen et al. ${ }^{(55)}$ \\
\hline & S/co1a4 & Chen et al. ${ }^{(55)}$, Tirona \& $\mathrm{Kim}^{(57)}$, Maglich et al. ${ }^{(58)}$ \\
\hline & СурЗа & Urquhart et al. ${ }^{(23)}$, Anger \& Piquette-Miller ${ }^{(43)}$, Chen et al. ${ }^{(55)}$, Tirona \& Kim ${ }^{(57)}$ \\
\hline & Сур2b & Urquhart et al. ${ }^{(23)}$, Chen et al. ${ }^{(5)}$, Tirona \& $\mathrm{Kim}^{(57)}$ \\
\hline & Cyp2c & Urquhart et al. ${ }^{(23)}$ Chen et al. ${ }^{(55)}$, Tirona \& Kim ${ }^{(57)}$ \\
\hline \multirow[t]{10}{*}{ CAR (NR1I3) } & $A b c b 1$ & Urquhart et al. ${ }^{(23)}$, Chen et al. ${ }^{(55)}$, Burk et al. ${ }^{(59)}$ \\
\hline & Abcc1 & Chen et al. ${ }^{(55)}$, Maglich et al. ${ }^{(58)}$ \\
\hline & $A b c c 2$ & Urquhart et al. ${ }^{(23)}$, Anger \& Piquette-Miller ${ }^{(43)}$, Chen et al..$^{(55)}$ \\
\hline & $A b c c 3$ & Anger \& Piquette-Miller ${ }^{(43)}$, Chen et al. ${ }^{(55)}$, Tirona \& Kim ${ }^{(57)}$ \\
\hline & $A b c c 4$ & Urquhart et al. ${ }^{(23)}$, Chen et al. ${ }^{(55)}$, Tirona \& $\mathrm{Kim}^{(57)}$ \\
\hline & $A b c c 5$ & Chen et al. ${ }^{(5)}$ \\
\hline & Сурза & Urquhart et al. ${ }^{(23)}$, Chen et al. ${ }^{(55)}$, Tirona \& Kim ${ }^{(57)}$ \\
\hline & Cyp2b & Urquhart et al. ${ }^{(23)}$, Chen et al. ${ }^{(55)}$ \\
\hline & Cyp2c & Urquhart et al. ${ }^{(23)}$, Chen et al. ${ }^{(55)}$, Tirona \& Kim ${ }^{(57)}$ \\
\hline & Cyp1a & Chen et al. ${ }^{(55)}$, Maglich et al. ${ }^{(58)}$ \\
\hline \multirow[t]{7}{*}{ FXR (NR1H4) } & $A b c c 2$ & Urquhart et al. (23) \\
\hline & $A b c b 11$ & Urquhart et al. ${ }^{(23)}$, Tirona $\& \mathrm{Kim}^{(57)}$ \\
\hline & $A b c b 4$ & Kalaany \& Mangelsdorf ${ }^{(26)}$, Tirona \& $\mathrm{Kim}^{(57)}$, Yin et al. ${ }^{(60)}$ \\
\hline & $A b c c 2$ & Kalaany \& Mangelsdorf ${ }^{(26)}$ \\
\hline & Cyp7a & Kalaany \& Mangelsdorf ${ }^{(26)}$ \\
\hline & SHP & Calkin \& Tontonoz ${ }^{(51)}$, Lefebvre et al. ${ }^{(52)}$ \\
\hline & Slco10a1 & Kalaany \& Mangelsdorf ${ }^{(26)}$ \\
\hline \multirow[t]{3}{*}{$\mathrm{LXR} \alpha(\mathrm{NR} 1 \mathrm{H} 3)$} & Abca1 & Kalaany \& Mangelsdorf ${ }^{(26)}$, Yin et al ${ }^{(60)}$ \\
\hline & $A b c a 5 / A b c a 8$ & Kalaany \& Manqelsdorf(26) \\
\hline & Srebp-1c & Kalaany \& Mangelsdorf ${ }^{(26)}$ \\
\hline
\end{tabular}

PXR, pregnane $X$ receptor; NR112, nuclear receptor subfamily 1, group I, member 2; Abcb1, ATP-binding cassette subfamily B member 1 ; Abcc2, ATP-binding cassette subfamily $\mathrm{C}$ member 2; Abcc3, ATP-binding cassette subfamily $\mathrm{C}$ member 3 ; Abcg2, ATP-binding cassette subfamily G member 2; Slco1a4, solute carrier organic anion transporter family, member 1a4; Cyp3a, cytochrome P450 3A; Cyp2b, cytochrome P450 2B; Cyp2c, cytochrome P450 2C; CAR, constitutive androstane receptor; NR1I3, nuclear receptor subfamily 1, group I, member 3; Abcc1, ATP-binding cassette subfamily C member 1; Abcc4, ATP-binding cassette subfamily C member 4; Abcc5, ATP-binding cassette subfamily C member 5; Cyp1a, cytochrome P450 1A; $\mathrm{NR} 1 \mathrm{H} 4$, nuclear receptor subfamily 1 , group $\mathrm{H}$, member 4; FXR, farnesoid X receptor; Abcb11, ATP-binding cassette subfamily B member 11; Abcb4, ATP-binding cassette subfamily B member 4; Cyp7a, cytochrome P450 7A; SHP, small heterodimer partner; SIco10a1, solute carrier organic anion transporter family, member 10A1; LXR $\alpha$, liver X receptor $\alpha$; NR1H3, nuclear receptor subfamily 1, group H, member 3; Abca1, ATP-binding cassette subfamily A member 1; Abcg5/Abcg8, ATP-binding cassette subfamily G member 5/8; Srebp-1c, sterol regulatory element-binding protein 1. 
acids. Farnesoid X receptor (FXR/NR1H4 (nuclear receptor subfamily 1 , group $\mathrm{H}$, member 4)) is a master regulator of bile acid homeostasis, responding to intracellular bile acid concentrations by promoting bile acid and phospholipid biliary secretion through the induction of the bile salt export pump ( $A B C B 11$ (ATP-binding cassette subfamily B member 11)) and $A B C B 4$ (ATP-binding cassette subfamily $\mathrm{B}$ member 4), respectively. FXR activation also indirectly suppresses the Na-dependent taurochlorate co-transporting protein (SLC10A1 (solute carrier family 10 (Na/bile acid co-transporter), member 1))-mediated uptake of bile into the liver through activation of the small heterodimer partner (SHP/NROB2 (nuclear receptor subfamily 0 , group B, member 2$))^{(26)}$.

As the involvement of nuclear receptors in regulating drug transporters and enzyme activity in diet-induced obesity is currently unclear, the objective of the present study was to investigate the effect of a HFD on the hepatic expression of the nuclear receptors $P X R, C A R, L X R$ and FXR and several of their target genes (Table 1). We hypothesised that high fat feeding would alter the hepatic gene expression of major transporters through a dysregulation of the expression of the nuclear receptors.

\section{Experimental methods}

\section{Animals}

Female Sprague-Dawley rats aged 6 weeks were purchased from Charles River. The rats were individually caged in a temperature- and humidity-controlled $12 \mathrm{~h}$ light- $12 \mathrm{~h}$ dark cycle, and allowed free access to food and water. The experiments were conducted in accordance with the Canadian Council on Animal Care. Female rats were randomised into two groups, either fed a HFD or a standard diet (SD) for a period of 13 weeks. The HFD consisted of $42 \cdot 8 \%$ energy from fat, $38.5 \%$ energy from carbohydrate and $18.7 \%$ energy from protein in the form of a pellet (TD 06092 ; Harlan Teklad). The SD consisted of $12.5 \%$ energy from fat, $63.2 \%$ energy from carbohydrate and $24.3 \%$ energy from protein in the form of a pellet of standard rat chow (5075; Charles River). Weight and food intake were monitored three times per week.

\section{Blood and tissue collection}

On week 13, the rats were killed between 09.00 and 12.00 hours, depending on the time at which food was removed. All food was removed from the cages at least $2-3 \mathrm{~h}$ before

Table 2. Quantitative PCR primers

\begin{tabular}{|c|c|c|}
\hline Genes & GenBank accession no. & Primer sequence \\
\hline$\beta$-Actin & NM_031144.2 & $\begin{array}{l}\text { Forward: 5'-GTCCACCCGCGAGTACAACCT-3' } \\
\text { Reverse: 5'-GTCATCCATGGCGAACTGGTGGC-3' }\end{array}$ \\
\hline Abcg5 & NM_053754.2 & $\begin{array}{l}\text { Forward: 5'-CTTCAGCGTCAGCAACCGTGTC-3' } \\
\text { Reverse: 5'-ATGCACATGGTCTGGCCACTCTC-3' }\end{array}$ \\
\hline$A b c b 4$ & NM_012690.1 & $\begin{array}{l}\text { Forward: 5'-TGAACTAGGCAGCATCAGCAACC-3' } \\
\text { Reverse: 5'-CCTGATCCGTGAGCTATGGCCAT-3' }\end{array}$ \\
\hline Abca1 & NM_178095.2 & $\begin{array}{l}\text { Forward: 5'-ACCGACAAGGCCGCACCATT-3' } \\
\text { Reverse: } 5^{\prime} \text {-GCCCACACAACACAGCTTCCCA-3' }\end{array}$ \\
\hline$A b c b 1 a$ & NM_133401.1 & $\begin{array}{l}\text { Forward: } 5^{\prime} \text {-GACGGAATTGATAATGTGGACA-3' } \\
\text { Reverse: } 5^{\prime} \text {-AAGGATCAGGAACAATAAA-3' }\end{array}$ \\
\hline$A b c c 2$ & NM_012833.1 & $\begin{array}{l}\text { Forward: 5'-GTCACGGCTTCCTTTCTG-3' } \\
\text { Reverse: 5'-AACCCCAACACCTGCTAA-3 }\end{array}$ \\
\hline$A b c c 3$ & NM_080581.1 & $\begin{array}{l}\text { Forward: 5'-GGAGTCTACGCCACCCTAGGA-3' } \\
\text { Reverse: 5'-GTGAAGGCCGACAGCATGA-3' }\end{array}$ \\
\hline$A b c b 11$ & NM_031760.1 & $\begin{array}{l}\text { Forward: 5'-GCAAATTCCGCTGCCTATAGA-3' } \\
\text { Reverse: 5'-CCCTGAAAACGTGGCTGAA-3' }\end{array}$ \\
\hline$P X R(N R 1 / 2)$ & NM_052980.2 & $\begin{array}{l}\text { Forward: 5'-GCTCCTGCTGGACCCGTTGA-3' } \\
\text { Reverse: 5'-GTACCACGCCAGGGCGATCTG-3' }\end{array}$ \\
\hline Сур7а1 & NM_012942.1 & $\begin{array}{l}\text { Forward: 5'-CTGCGAAGGCATTTGGACACAGA-3' } \\
\text { Reverse: 5'-GCATCTCCCTGGAGGGTTTTGGT-3' }\end{array}$ \\
\hline$L X R \alpha(N R 1 H 3)$ & NM_031627.2 & $\begin{array}{l}\text { Forward: 5'-AGTCACGCCTTGGCCCATTGC- } 3^{\prime} \\
\text { Reverse: } 5^{\prime} \text {-CGGACACGATGGCCAGCTCA- } 3^{\prime}\end{array}$ \\
\hline$L X R \beta(N R 1 H 2)$ & NM_031626.1 & $\begin{array}{l}\text { Forward: 5'-GGCCGGGAGGACCAGAT-3' } \\
\text { Reverse: } 5^{\prime} \text {-GCGTCTGGCTGTCTCTAGCAA-3' }\end{array}$ \\
\hline$F X R(N R 1 H 4)$ & NM_021745.1 & $\begin{array}{l}\text { Forward: 5'-CCGCAGTCGAGGCCATGTTCC-3' } \\
\text { Reverse: 5'-TCATCGGAGATGCCGCTCTTTCG-3' }\end{array}$ \\
\hline SHP (NROB2) & $\mathrm{BC} 088117$ & $\begin{array}{l}\text { Forward: 5'-CCTTGGCTAGCTGGGTACCA-3' } \\
\text { Reverse: 5'-GTCCCAAGGAGTACGCATACCT-3' }\end{array}$ \\
\hline CRP & NM_017096.3 & $\begin{array}{l}\text { Forward: 5'-GGCGGTGGCTTTGACGCGAA-3' } \\
\text { Reverse: } 5^{\prime} \text {-ACTTCAGTGCCCGCCAGTTCA-3' }\end{array}$ \\
\hline
\end{tabular}

Abcg5, ATP-binding cassette subfamily G member 5; Abcb4, ATP-binding cassette subfamily B member 4; Abca1, ATPbinding cassette subfamily A member 1; Abcb1a, ATP-binding cassette subfamily B member 1a; Abcc2, ATP-binding cassette subfamily $\mathrm{C}$ member 2 ; $A b c c 3$, ATP-binding cassette subfamily $\mathrm{C}$ member 3 ; Abcb11, ATP-binding cassette subfamily B member 11; PXR, pregnane X receptor; NR1I2, nuclear receptor subfamily 1, group I, member 2; Cyp7a1, cytochrome P450 7A1; $L X R \alpha$, liver $X$ receptor $\alpha ; N R 1 H 3$, nuclear receptor subfamily 1 , group $\mathrm{H}$, member $3 ; L X R \beta$, liver $\mathrm{X}$ receptor $\beta ; N R 1 H 2$, nuclear receptor subfamily 1 , group $\mathrm{H}$, member $2 ; F X R$, farnesoid $\mathrm{X}$ receptor; $N R 1 H 4$, nuclear receptor subfamily 1 , group $\mathrm{H}$, member 4 ; $S H P$, small heterodimer partner; $N R O B 2$, nuclear receptor subfamily 0 , group $\mathrm{B}$, member 2; CRP, C-reactive protein. 
sacrificing. After complete anaesthesia with isoflurane, the abdominal cavity was opened and approximately $5 \mathrm{ml}$ of blood were withdrawn from the abdominal vena cava into 15\% EDTA pre-treated tubes. To collect plasma samples, whole blood was then centrifuged at $3000 \mathrm{rpm}$ for $10 \mathrm{~min}$ at $4^{\circ} \mathrm{C}$ (Allegra 6R Centrifuge; Beckman Coulter) and then immediately stored at $-80^{\circ} \mathrm{C}$. The liver median lobe was weighed, freeze-clamped and stored at $-80^{\circ} \mathrm{C}$ for further use. Fat depots were collected from the urogenital, retroperitoneal and subcutaneous regions.

\section{Blood chemistry}

Plasma levels of free fatty acid (non-esterified fatty acid, NEFA), insulin, glucose, cholesterol, leptin, TAG and glycerol were measured as described previously ${ }^{(27,28)}$. Briefly, plasma insulin and leptin concentrations were determined with RIA test kits distributed by LINCO Research, plasma glucose concentrations were measured using the Autokit Glucose enzymatic colorimetric assay (Wako Diagnostics), and plasma NEFA concentration was determined using an enzymatic colorimetric assay (Roche Diagnostics). Plasma total cholesterol concentration was determined using a commercial kit (Wako Diagnostics and Chemicals USA) according to the manufacturer's instructions. Commercial kits (Sigma) were used to determine glycerol and TAG levels in plasma and hydrolysed liver homogenate samples by colorimetric methods. The analysis of plasma bile acid concentration was performed by IDEXX Laboratories. Total hepatic bile acid concentrations were determined in $100 \mathrm{mg}$ liver samples by homogenising in $75 \%$ ethanol followed by incubation for $2 \mathrm{~h}$ at $50^{\circ} \mathrm{C}$. The samples were centrifuged at $6000 \mathrm{~g}$ and the supernatant was used for the determination of total bile acid concentrations according to the manufacturer's protocol (Crystal Chem, Inc.).

\section{$P C R$}

Total RNA was extracted from $100 \mathrm{mg}$ of frozen liver tissue using TRIzol reagent (Invitrogen), according to the manufacturer's instructions, and absorbance was measured at 260 and $280 \mathrm{~nm}$ (NanoDrop; Thermo Fisher Scientific). Total RNA $(2 \mu \mathrm{g})$ was treated with deoxyribonuclease I (Invitrogen) and reverse transcribed with the High-Capacity cDNA Reverse Transcription Kit (Applied Biosystems). Primer sets were synthesised at the Hospital for Sick Children (DNA Synthesis Center; Table 2). Real-time quantitative PCR was performed using LightCycler ${ }^{\circledR}$ technology with SYBR Green I fluorescence detection (Roche Diagnostics). A sample without the reverse transcription enzyme and a no-template control was used to detect genomic or DNA contamination. An efficiency-corrected $\Delta C_{\mathrm{t}}$ method was used to calculate the relative amounts of RNA, and amplification efficiency was calculated using the equation $E=10^{(-1 / \text { slope })}$. mRNA levels were normalised to those of $\beta$-actin, and results are presented as a percentage of control values.

\section{Western blot analysis}

Protein extraction was performed by methods as described previously ${ }^{(29,30)}$. Briefly, $300 \mathrm{mg}$ of liver tissue were
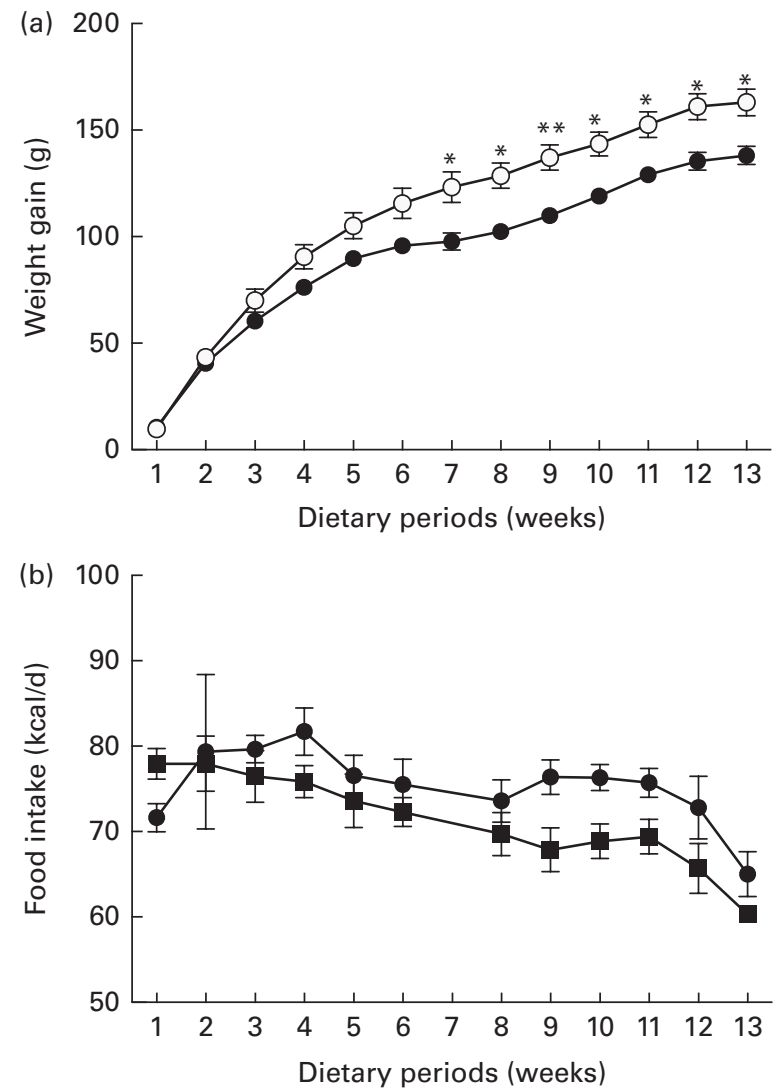

Fig. 1. (a) Average weight gain (g) and (b) weekly food intake (kcal/d) of rats. Female rats were fed a high-fat diet ((a) $-O-$ and (b) - - -) or a standard diet (--) for 13 weeks as described in the 'Experimental methods' section. Values are means ( $n 7)$, with their standard errors represented by vertical bars. Mean value was significantly different from that of the SD group: ${ }^{\star} P<0.05$, ${ }^{\star *} P<0.01$. To convert food intake in $\mathrm{kcal} / \mathrm{d}$ to $\mathrm{kJ} / \mathrm{d}$, multiply by $4 \cdot 184$.

homogenised in $1 \times$ RIPA (radioimmunoprecipitation assay) lysis buffer (Cell Signaling Technology) with freshly added 0.5 mm-phenylmethylsulfonyl fluoride (Bioshop) and $4 \mu \mathrm{l} / \mathrm{ml}$ protease inhibitor (P8340; Sigma-Aldrich). Protein concentrations were quantified by the Bradford assay. A total of $20 \mu \mathrm{g}$ of membrane protein or $60 \mu \mathrm{g}$ of whole cell lysate in Laemmli sample buffer (Bio-Rad) for Pgp and Cyp3a2, respectively, were separated by $10 \%$ SDS-PAGE and transferred to polyvinylidene fluoride membranes (Bio-Rad Laboratories Canada Limited). The membranes were blocked for $1 \mathrm{~h}$ in $5 \%(\mathrm{w} / \mathrm{v})$ skimmed milk powder in Tris-buffered saline containing $0.05 \%(\mathrm{v} / \mathrm{v})$ Tween-20, and then incubated at $4{ }^{\circ} \mathrm{C}$ overnight with mouse anti-Pgp antibody (C-219, 1:500, $1 \mathrm{mg} / \mathrm{ml}$; Abcam, Inc.), rabbit anti-Cyp3a2 (ab78279, 1:1000; Abcam, Inc.) or goat anti-PXR.1 (A-20, 1:100, 0.2 mg/ml; Santa Cruz Biotechnology, Inc.). After a series of washes with Tris-buffered saline, the membranes were incubated for $2 \mathrm{~h}$ with secondary antibodies from Jackson ImmunoResearch Laboratories (goat anti-mouse at 1:3000 for Pgp, goat anti-rabbit at 1:5000 for Cyp3a2 and donkey anti-goat at 1:2000 for PXR.1). The membranes were visualised with ECL Plus (GE Healthcare) using a FluorChem imaging system (Alpha Innotech), and the optical density of each 
band was determined with the AlphaEaseFC software (Alpha Innotech). $\beta$-Actin (AC-15, 1:40 000, $2 \mathrm{mg} / \mathrm{ml}$; Sigma-Aldrich) was used as a housekeeping gene to correct for variability in protein loading.

\section{Data and statistical analysis}

Data were analysed with GraphPad Prism version 5 (GraphPad Software, Inc.). A two-tailed Student' $t$ test was used to compare the results between the HFD and SD rats. Significance was set at $P<0.05$. Data are presented as means with their standard errors of the mean. Correlation was performed using Pearson's correlation test.

\section{Results}

\section{Body composition and metabolic characteristics}

Compared with the SD group, rats fed the HFD gained significantly more weight after 6 weeks of commencing the diet until the end of the study $(P<0.05$; Fig. 1(a)). Differences in weight gain between the two groups increased with time. The initial weight of the rats was 210.3 (SEM 1.8) $\mathrm{g}$ in the SD group and 209.0 (SEM 1.9) $\mathrm{g}$ in the HFD group, while the final weight of the rats was 348.4 (SEM 5.9) $\mathrm{g}$ in the SD group and 372.1 (SEm 7.3) g in the HFD group. A similar intake of energy was observed between the two groups (Fig. 1(b)). A significant gain in intra-abdominal and subcutaneous fat mass was observed in the HFD group $(P<0.05)$ (Table 3).

Blood chemistry of the HFD group showed a trend towards mild hyperlipidaemia with significantly higher levels of cholesterol, NEFA and glycerol in the HFD group compared with the SD group. Plasma TAG levels were also somewhat elevated in the HFD group, but did not reach significance (Table 3). Total hepatic bile acid concentrations were not different between the HFD (0.42 (SEM 0.04) $\mu \mathrm{mol} / \mathrm{g})$ and SD (0.45 (sEm 0.08) $\mu \mathrm{mol} / \mathrm{g})$ groups.

\section{Effect of the high-fat diet on cytokine expression}

Hepatic mRNA levels of $I L-1 \beta$ and $I L-6$ were not significantly different between the HFD and SD groups; however, mRNA levels of $\mathrm{C}$-reactive protein $(C R P)$, which is a biomarker for IL-6 activity and systemic inflammation, were significantly higher in the HFD group (Fig. 2).

\section{Effect of the high-fat diet on nuclear receptor expression}

We observed significant differences in the hepatic expression of key nuclear receptors in rats fed the HFD (Fig. 3). Compared with the SD group, the rats fed the HFD had a 2-fold increase in the expression of $P X R$ and FXR $(P<0.05)$. The expression levels of both $L X R \alpha$ and $L X R$ were slightly but significantly increased in rats fed the HFD $(P<0 \cdot 05)$. However, the expression level of $C A R$ was not significantly affected.

\section{Target genes of pregnane $X$ receptor}

The HFD had a pronounced effect on the expression of several target genes of PXR (Fig. 4(a)). Compared with the SD group, a 2 - and 5-fold increase in the hepatic expression of the canalicular efflux transporters Abcc2 (ATP-binding cassette subfamily C member 2) and Abcb1a (ATP-binding cassette subfamily B member 1a) was observed in rats fed the HFD. While the mRNA expression of the apical uptake transporter Slco1a4 (solute carrier organic anion transporter family, member 1a4) was significantly higher in the HFD group, the expression levels of $A b c c 3$ (ATP-binding cassette subfamily $\mathrm{C}$ member 3) were significantly decreased $(P<0 \cdot 05)$. The mRNA expression level of Cyp3a2 was $2 \cdot 5$-fold higher in the HFD group than in the SD group. The increased expression levels of these genes were strongly correlated with the increased expression levels of PXR (Pearson's $r>0.67$; Abcb1a $(P=0.0002), \quad A b c c 2 \quad(P=0.002), \quad$ Slco1a4 $(P=0.009)$ and Cyp3a2 $(P=0 \cdot 012))$. Changes in the expression levels of Cyp3a2 and Pgp were further confirmed at the protein level (Fig. 4(b) and (c)).

Table 3. Body composition and metabolic characteristics of female rats fed a high-fat diet (HFD) or a standard diet (SD) for 13 weeks

(Mean values with their standard errors)

\begin{tabular}{|c|c|c|c|c|}
\hline \multirow[b]{2}{*}{ Characteristic } & \multicolumn{2}{|c|}{ SD } & \multicolumn{2}{|c|}{ HFD } \\
\hline & Mean & SEM & Mean & SEM \\
\hline Food intake $(\mathrm{g} / \mathrm{d})$ & $22 \cdot 2$ & 0.4 & 18.45 & 0.4 \\
\hline Food intake $(\mathrm{kcal} / \mathrm{d})$ & 75.4 & 1.4 & $70 \cdot 1$ & 1.7 \\
\hline Liver triglycerides $(\mathrm{mg} / \mathrm{g})$ & 11.3 & 0.4 & $12 \cdot 2$ & 0.9 \\
\hline Intra-abdominal fat-pad weight (sum of 3 in g) & $30 \cdot 8$ & $2 \cdot 8$ & $35 \cdot 8^{*}$ & $2 \cdot 9$ \\
\hline Subcutaneous fat-pad weight (g) & 1.5 & $0 \cdot 18$ & $2 \cdot 4^{*}$ & 0.24 \\
\hline Plasma triglycerides $(\mathrm{g} / \mathrm{l})$ & 54.5 & $6 \cdot 3$ & $82 \cdot 4$ & 13.9 \\
\hline Plasma total cholesterol (mmol/l) & $3 \cdot 15$ & 0.12 & $4 \cdot 17^{\star *}$ & 0.24 \\
\hline Non-esterified fatty acids (mmol/l) & 0.50 & 0.01 & $0.54^{*}$ & 0.01 \\
\hline Glycerol $(g / l)$ & 0.02 & 0.002 & $0.03^{*}$ & 0.005 \\
\hline Insulin (ng/ml) & 2.33 & 0.7 & 1.54 & 0.4 \\
\hline Leptin (ng/ml) & $12 \cdot 8$ & $2 \cdot 8$ & $15 \cdot 4$ & $2 \cdot 3$ \\
\hline Glucose $(\mathrm{mmol} / \mathrm{l})$ & $12 \cdot 33$ & 0.55 & 11.57 & 0.46 \\
\hline Bile acids $(\mu \mathrm{mol} / \mathrm{l})$ & 15 & $2 \cdot 7$ & 13.5 & 1.9 \\
\hline
\end{tabular}

Mean value was significantly different from that of the SD group: ${ }^{\star} P<0.05,{ }^{\star \star} P<0.01$. 


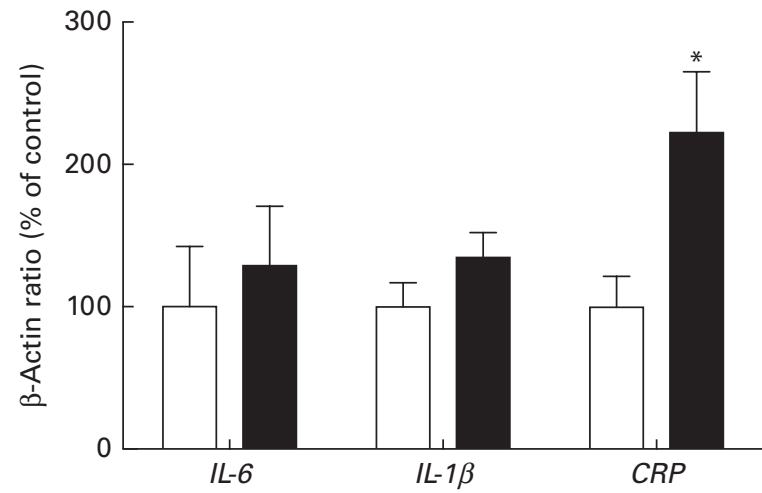

Fig. 2. Hepatic mRNA expression of pro-inflammatory cytokines in female rats fed a high-fat diet ( $\square$ ) or a standard diet $(\square)$ for 13 weeks, as determined by real-time quantitative PCR. Values are expressed as a percentage of the control value $(100 \%)$. Values are means $(n 7)$, with their standard errors represented by vertical bars. ${ }^{\star}$ Mean value was significantly different from that of the SD group: $(P<0.05)$. CRP, C-reactive protein

\section{Target genes of farnesoid $X$ receptor}

As the expression levels of FXR were significantly increased in the HFD group, the expression levels of several target genes of FXR involved in bile acid homeostasis were examined (Fig. 5). Compared with the SD group, an approximately 2- and 3-fold increase in the mRNA levels of $A b c b 11$ and $A b c b 4$, respectively, was observed in rats fed the HFD. The increased expression levels of these genes were strongly correlated with the expression levels of FXR in both groups (Pearson's $r>0.83 ; A b c b 11(P<0.0001)$ and $A b c b 4$ $(P=0 \cdot 0001))$. The expression level of the small heterodimer partner (SHP), which is transcriptionally increased as a result of FXR activation, was found to be 2.5-fold higher in the HFD group than in the SD group $(P<0.05)$. Surprisingly, the expression level of Slc1Oa1, which is negatively regulated by FXR through SHP mediated repression, was found to be significantly increased in the HFD group. In contrast, the expression level of Cyp7a1, a metabolic enzyme involved in cholesterol synthesis, was not significantly different between the groups.

\section{Target genes of liver $X$ receptor}

The effect of the HFD on the expression of LXR target genes is shown in Fig. 6. The canalicular ABC half-transporters Abcg5 and $A b c g 8$ act in unison to efflux cholesterol into the bile. Although a pronounced increase in the expression level of $A b c g 5$ was observed in the HFD group compared with the SD group, the expression levels of $A b c g 8$ were not significantly affected. The HFD also significantly increased the mRNA levels of the cholesterol efflux regulatory protein (CERP/Abca1). In conjunction with ApoAI, CERP/Abca1 is involved in the transfer of cholesterol from macrophages into hepatocytes.

\section{Discussion}

Similar to our previous findings ${ }^{(30)}$, we found that rats fed a HFD ( $42 \%$ energy from fat) for a period of 13 weeks had a higher weight gain and larger intra-abdominal fat mass compared with those fed a SD; however, the total lipid content in the liver did not change, as determined by biochemical and histological analysis of TAG levels in the liver ${ }^{(31)}$. This result is in agreement with previous studies showing that liver TAG levels increase during the first weeks of high fat feeding, but then gradually return to normal levels ${ }^{(28,31)}$, which suggests that there are mechanisms by which the liver adapts to increased dietary lipids ${ }^{(31)}$

Altered hepatobiliary transport of endogenous and exogenous compounds has previously been reported in transgenic and dietary rodent models of obesity ${ }^{(10,15,32-34)}$. The HFD, most commonly referred to as the Western-style diet, is currently the leading cause of obesity and its associated co-morbidities ${ }^{(35-37)}$. The main findings of the present study were that high fat feeding in female rats, which was associated with increased total weight and intra-abdominal fat, was accompanied by an increase in the gene expression levels of several nuclear receptors. HFD-induced changes in nuclear receptors were further associated with an increase in the expression levels of their target genes, including numerous hepatobiliary transporters. While the lack of a universal definition of diet-induced obesity in rodents might allow the HFD rats to be considered obese, in relation to human obesity and other diet-induced obesity models in rats, and the difference in body weight observed between the two groups in the present study (11.3\%), the HFD rats should be described as mildly obese or overweight.

The present study demonstrated that the HFD induced a significant increase in the expression levels of the nuclear receptor $P X R$ and its target genes. A strong correlation was also observed between the expression levels of these genes. The mRNA and protein expression levels of Pgp and Cyp3a2, which are key target genes of $\operatorname{PXR}^{(38)}$, were significantly increased in the HFD group. While PXR activation has been reported in the $o b / o b$ mouse model of obesity ${ }^{(13)}$, the present study was the first to observe PXR activation and

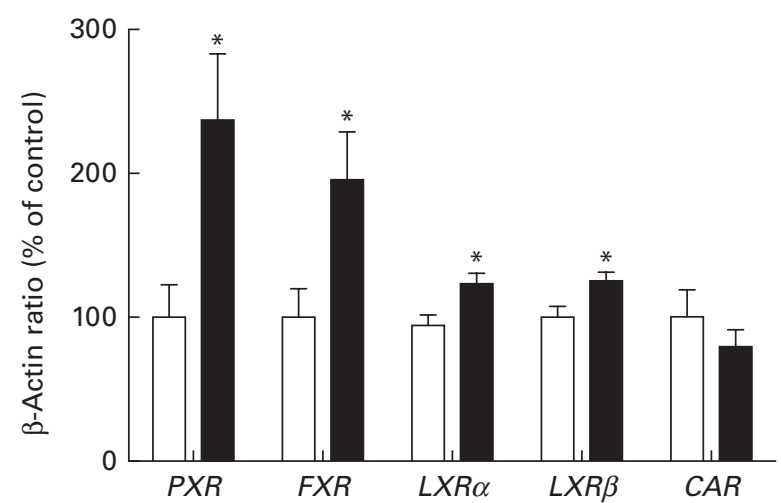

Fig. 3. Hepatic mRNA expression of nuclear receptors in female rats fed a high-fat diet $(\square)$ or a standard diet $(\square)$ for 13 weeks, as determined by real-time quantitative PCR. Values are expressed as a percentage of the control value $(100 \%)$. Values are means $(n 7)$, with their standard errors represented by vertical bars. ${ }^{*}$ Mean value was significantly different from that of the SD group: $(P<0.05) . P X R$, pregnane $X$ receptor; $F X R$, farnesoid $X$ receptor; $L X R \alpha$, liver $X$ receptor $\alpha ; L X R \beta$, liver $X$ receptor $\beta ; C A R$, constitutive androstane receptor. 
(a)

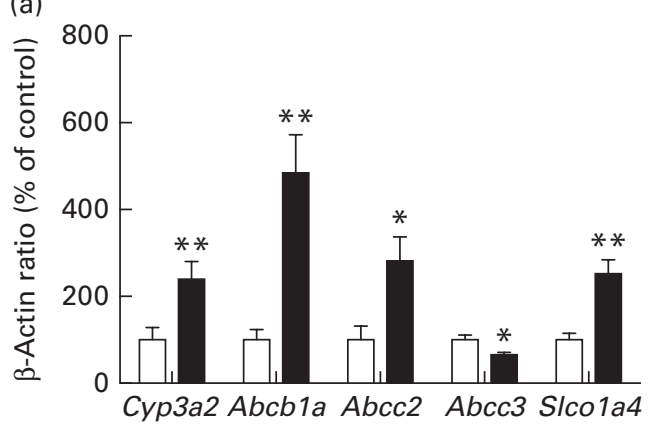

(b)

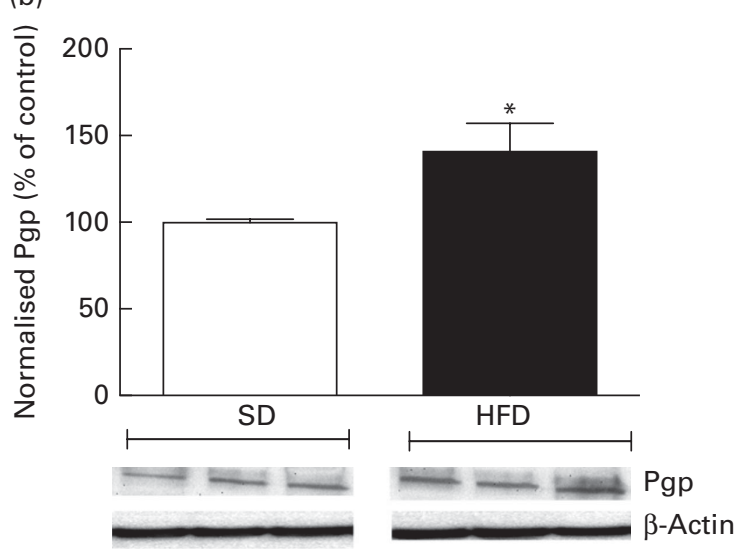

(c)

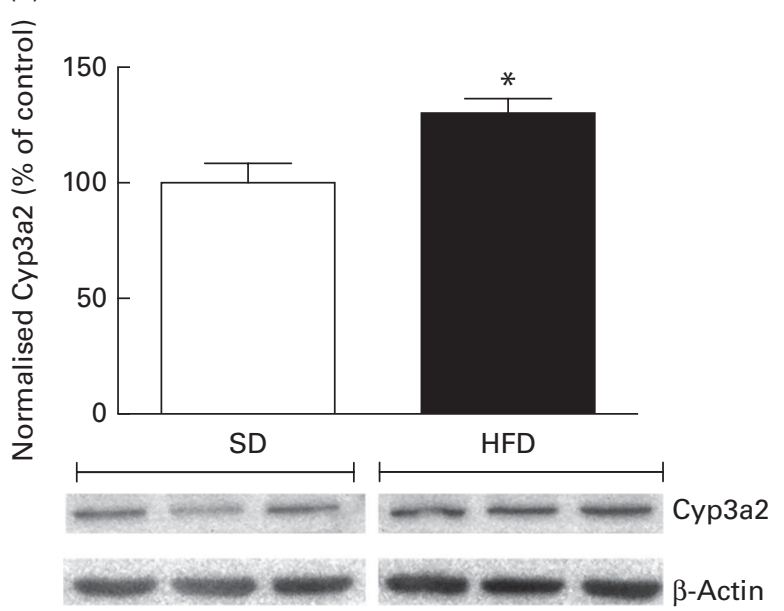

Fig. 4. (a) Hepatic mRNA expression of the target genes of pregnane $X$ receptor in rats fed a high-fat diet (HFD, $\mathbf{\square})$ and a standard diet (SD, $\square$ ), as determined by real-time quantitative PCR. Values are expressed as a percentage of the control value $(100 \%)$. Values are means $(n 7)$, with their standard errors represented by vertical bars. Mean value was significantly different from that of the SD group: ${ }^{*} P<0.05,{ }^{\star \star} P<0.01$. Hepatic protein expression of (b) P-glycoprotein (Pgp) and (c) Cyp3a2 (cytochrome P450 3A2) in rats fed a HFD and SD. Protein levels were determined by Western blot analysis and normalised to those of $\beta$-actin. Abcb1a, ATP-binding cassette subfamily B member 1a; Abcc2, ATP-binding cassette subfamily C member 2; Abcc3, ATP-binding cassette subfamily C member 3; Slco1a4, solute carrier organic anion transporter family, member 1a4.

induction of target genes such as Pgp and Cyp3a2 in mildly obese rats. Sugioka et $a l^{(32)}$ reported that diet-induced obesity imposed a decrease in the protein expression of Pgp and Cyp3a2 in male rats. However, they utilised a high-fat/high-cholesterol diet containing cholic acid, which is known to be associated with hepatic steatosis ${ }^{(19,39,40)}$. We did not find any evidence for hepatic steatosis in our HFD model. Thus, discrepancies between the present results and previous findings could result from the differences in the models used to induce obesity and the time points of the investigation. PXR and CAR play a key role in energy metabolism in the liver and could possibly act as a link between energy homeostasis and drug metabolism ${ }^{(41)}$. It has previously been suggested that accumulation of dietary fatty acids in the liver triggers the activation of PXR, leading to the induction of cytochrome P450 enzymes ${ }^{(42,43)}$. It is possible that the increased levels of fatty acids observed in our HFD rats could have contributed to PXR activation and up-regulation of their target genes. High fat feeding was also associated with a substantial increase in the plasma concentrations of cholesterol, which probably contributes to PXR activation as recent studies have shown that PXR is activated by oxysterols, which are the oxidised derivatives of cholesterol ${ }^{(44,45)}$. With regard to the clinical implications of these findings, Сyp3a2, which corresponds to CYP3A in humans ${ }^{(46)}$, is responsible for the metabolism of the majority of drugs currently on the market ${ }^{(47)}$ Pgp also plays a key role in the hepatobiliary clearance of many structurally diverse compounds including many anticancer, antiviral and anti-arrythmic drugs ${ }^{(48)}$. Thus, it is plausible that PXR activation, resulting in the induction of CYP3A and Pgp, could increase the clearance of numerous drugs.

The present study demonstrated a significant elevation in the expression of the nuclear receptor FXR, the principal regulator of bile acid homeostasis. This correlated with the increased expression levels of its target genes $A b c b 4$, $A b c b 11$ and Slco10a1 in response to the HFD. Slco10a1 and $A b c b 11$ are the principal uptake and efflux transporters of bile acids. In contrast, $A b c b 4$ is responsible for the efflux of phospholipids into bile, making it more lipophilic and less damaging to biliary cells ${ }^{(48,49)}$. The HFD was also associated

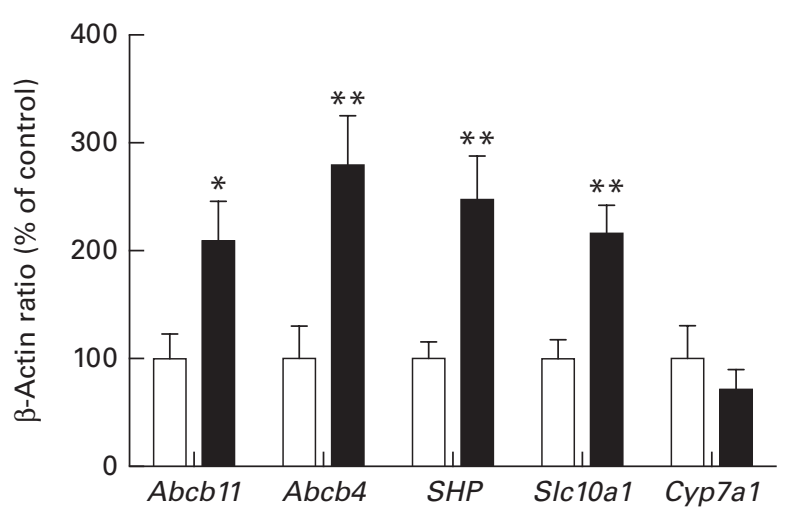

Fig. 5. Hepatic mRNA expression of the target genes of farnesoid $X$ receptor in rats fed a high-fat diet $(\boldsymbol{\square})$ or a standard diet $(\square)$, as determined by real-time quantitative PCR. Values are expressed as a percentage of the control value $(100 \%)$. Values are means $(n 7)$, with their standard errors represented by vertical bars. Mean value was significantly different from that of the SD group: ${ }^{*} P<0.05,{ }^{* *} P<0.01$. Abcb11, ATP-binding cassette subfamily B member $11 ; A b c b 4$, ATP-binding cassette subfamily B member 3; SHP, small heterodimer partner; Slc10a1, solute carrier family 10 (Na/bile acid co-transporter), member 1; Cyp7a1, cytochrome P450 7A1. 


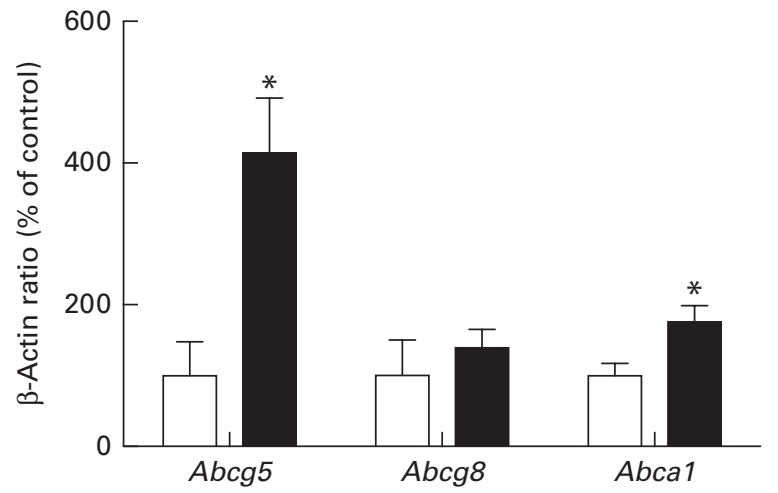

Fig. 6. Hepatic mRNA expression of the target genes of liver $\mathrm{X}$ receptor in rats fed a high-fat diet $(\square)$ or a standard diet $(\square)$, as determined by real-time quantitative PCR. Values are expressed as a percentage of the control value $(100 \%)$. Values are means $(n 7)$, with their standard errors represented by vertical bars. Mean value was significantly different from that of the SD group: * $P<0.05$. Abcg5, ATP-binding cassette subfamily $\mathrm{G}$ member 5; Abcg8, ATP-binding cassette subfamily G member 8; Abca1, ATP-binding cassette subfamily A member 1.

with an increased expression level of $A b c c 2$, which is regulated by FXR as well as by PXR and CAR ${ }^{(50)}$. The efflux transporter $A b c c 2$ is involved in the transport of drugs, bilirubin, glucouronide and glutathione drug conjugates in addition to bile constituents. The underlying cause of FXR induction and activation in our overweight rats is not clear. The principal activator of FXR is bile acids ${ }^{(49)}$. While several changes were observed in the expression of bile acid transporters, we did not observe any significant changes in the liver or plasma concentrations of bile acids in the HFD group. Nevertheless, it is possible that HFD-induced changes could have resulted in bile acid retention at an earlier time point as FXR activation leads to negative feedback inhibition to normalise bile acid levels by increasing the efflux of bile acids from hepatocytes and decreasing de novo synthesis of bile from cholesterol ${ }^{(51,52)}$. This could explain our findings of FXR-mediated induction of $A b c b 11, A b c c 2$ and $A b c b 4$, which would lead to an increased efflux of bile and bile acids from hepatocytes. The up-regulation of Slco10a1 could increase hepatobiliary clearance and normalise serum bile acid level. Likewise, More \& Slitt ${ }^{(33)}$ reported an increase in the hepatic expression levels of $A b c c 2$ as well as Slco1a4 in a diet-induced murine model of obesity. In addition, Martin et al. ${ }^{(13)}$ reported an increase in the mRNA levels of $A b c c 2, A b c b 11$ and FXR in an $o b / o b$ mouse model.

The results from the present study show that total cholesterol levels were significantly elevated in the HFD group, as well as an increased expression level of the cholesterol transporters $A b c a 1$ and $A b c g 5$. The nuclear receptor LXR, which is activated by cholesterol derivatives such as oxysterols ${ }^{(51)}$, is involved in the induction of the expression levels of $A b c a 1$, Abcg5, Abcg8 and Cyp7a1, leading to increased serum cholesterol levels. The expression of Cyp7a1, which was not significantly affected by the HFD in the present study, is regulated by both $\mathrm{LXR}$ and $\mathrm{FXR}^{(53,54)}$. While $\mathrm{LXR}$ activation causes the induction of Cyp7a1, FXR activation suppresses its expression. Our findings demonstrating an increased expression level of both $F X R$ and $L X R \alpha / L X R \beta$ probably contribute to the overall effect of the HFD on the expression level of Cyp $7 a 1$

In conclusion, the present study demonstrates that the HFD increases the hepatic expression levels of $P X R, L X R \alpha, L X R \beta$ and FXR as well as their activation, as illustrated by the induction of their key target genes. The HFD was also associated with changes in plasma lipid profiles, as well as with the hepatic expression levels of several uptake and efflux transporters along with the metabolic enzyme Cyp3a2. This suggests that mild obesity may trigger changes in the hepatobiliary transport and clearance of both endogenous and exogenous compounds. The results from the present study and those from different models of obesity indicate that obesity is a complex condition with several co-morbidities that might affect hepatobiliary disposition pathways. If these findings in rodent models translate to humans with mild obesity, the distribution and clearance of many clinically important therapeutics could be affected in patients.

\section{Acknowledgements}

The present study was funded by an operating grant from the Natural Sciences and Engineering Research Council of Canada (7594) and from the Canadian Institutes of Health Research (M. P.-M.: MOP 57688; J.-M. L.: T 0602 145·02). R. H. G. was a recipient of King Abdulaziz University Scholarship for Postgraduate studies.

The authors' contributions are as follows: R. H. G., E. T. N. S., M. P.-M. and J.-M. L. contributed to the experimental design; R. H. G. and E. T. N. S. performed the experiment and data analysis; R. H. G., J.-M. L. and M. P.-M. wrote the paper.

There are no conflicts of interest to declare.

\section{References}

1. World Health Organization (WHO) (2011) Obesity and Overweight. Geneva: WHO.

2. Hubert HB, Feinleib M, McNamara PM, et al. (1983) Obesity as an independent risk factor for cardiovascular disease: a 26-year follow-up of participants in the Framingham Heart Study. Circulation 67, 968-977.

3. Rasouli N \& Kern PA (2008) Adipocytokines and the metabolic complications of obesity. J Clin Endocrinol Metab 93, 11 Suppl. 1, S64-S73.

4. March of Dimes (2004) Maternal obesity and pregnancy: weight matters. http://www.marchofdimes.com/files/MP_ Maternal obesity040605.pdf (accessed 14 August 2006).

5. Galtier-Dereure F, Boegner C \& Bringer J (2000) Obesity and pregnancy: complications and cost. Am J Clin Nutr $\mathbf{7 1}$, 5 Suppl., 1242S-1248S.

6. Madan J, Chen M, Goodman E, et al. (2010) Maternal obesity, gestational hypertension, and preterm delivery. J Matern Fetal Neonatal Med 23, 82-88.

7. Boullata JI (2010) Drug disposition in obesity and proteinenergy malnutrition. Proc Nutr Soc 69, 543-550.

8. Crum-Cianflone NF, Roediger M, Eberly LE, et al. (2010) Obesity among HIV-infected persons: impact of weight on CD4 cell count. AIDS 24, 1069-1072. 
9. Jain R, Chung SM, Jain L, et al. (2011) Implications of obesity for drug therapy: limitations and challenges. Clin Pharmacol Therap 90, 77-89.

10. Pizarro M, Balasubramaniyan N, Solis N, et al. (2004) Bile secretory function in the obese Zucker rat: evidence of cholestasis and altered canalicular transport function. Gut 53, 1837-1843.

11. Geier A, Dietrich CG, Grote T, et al. (2005) Characterization of organic anion transporter regulation, glutathione metabolism and bile formation in the obese Zucker rat. $J$ Hepatol 43, 1021-1030.

12. Cheng Q, Aleksunes LM, Manautou JE, et al. (2008) Drug-metabolizing enzyme and transporter expression in a mouse model of diabetes and obesity. Mol Pharm 5, 77-91.

13. Martin Schmitt J IV, Minkenberg A, et al. (2010) Bile acid retention and activation of endogenous hepatic farnesoid$\mathrm{X}$-receptor in the pathogenesis of fatty liver disease in ob/ob-mice. Biol Chem 391, 1441-1449.

14. Sabeva NS, Liu J \& Graf GA (2009) The ABCG5 ABCG8 sterol transporter and phytosterols: implications for cardiometabolic disease. Curr Opin Endocrinol Diabetes Obes 16, $172-177$.

15. Gylling H, Hallikainen M, Kolehmainen M, et al. (2007) Cholesterol synthesis prevails over absorption in metabolic syndrome. Transl Res 149, 310-316.

16. Gylling H \& Miettinen TA (2005) Cholesterol absorption: influence of body weight and the role of plant sterols. Curr Atheroscler Rep 7, 466-471.

17. Attia N, Fournier N, Vedie B, et al. (2010) Impact of android overweight or obesity and insulin resistance on basal and postprandial SR-BI and ABCA1-mediated serum cholesterol efflux capacities. Atherosclerosis 209, 422-429.

18. Satia-Abouta J, Patterson RE, Schiller RN, et al. (2002) Energy from fat is associated with obesity in U.S. men: results from the Prostate Cancer Prevention Trial. Prev Med 34, 493-501.

19. Angela M, Gajda MAP, Mathew R, et al. (2007) Diet-induced metabolic syndrome in rodent models. Animal Lab News Magazine. Amherst, NH: Vicon Business Media.

20. Trauner M, Arrese M \& Wagner M (2010) Fatty liver and lipotoxicity. Biochim Biophys Acta 1801, 299-310.

21. Gregor MF \& Hotamisligil GS (2011) Inflammatory mechanisms in obesity. Annu Rev Immunol 29, 415-445.

22. Teng S \& Piquette-Miller M (2008) Regulation of transporters by nuclear hormone receptors: implications during inflammation. Mol Pharm 5, 67-76.

23. Urquhart BL, Tirona RG \& Kim RB (2007) Nuclear receptors and the regulation of drug-metabolizing enzymes and drug transporters: implications for interindividual variability in response to drugs. J Clin Pharmacol 47, 566-578.

24. Im SS \& Osborne TF (2011) Liver X receptors in atherosclerosis and inflammation. Circ Res 108, 996-1001.

25. Sonoda J, Pei L \& Evans RM (2008) Nuclear receptors: decoding metabolic disease. FEBS Lett 582, 2-9.

26. Kalaany NY \& Mangelsdorf DJ (2006) LXRS and FXR: the yin and yang of cholesterol and fat metabolism. Ann Rev Physiol 68, 159-191.

27. Gauthier MS, Couturier K, Latour JG, et al. (2003) Concurrent exercise prevents high-fat-diet-induced macrovesicular hepatic steatosis. J Appl Physiol 94, 2127-2134.

28. Collin P, Chapados N, Dufresne E, et al. (2006) Time course of changes in in vitro lipolysis of intra-abdominal fat depots in relation to high-fat diet-induced hepatic steatosis in rats. BrJ Nutr 96, 268-275.

29. Anger GJ, Cressman AM \& Piquette-Miller M (2012) Expression of $\mathrm{ABC}$ efflux transporters in placenta from women with insulin-managed diabetes. PLOS ONE 7, e35027.

30. De Souza R, Zahedi P, Badame RM, et al. (2011) Chemotherapy dosing schedule influences drug resistance development in ovarian cancer. Mol Cancer Ther 10, 1289-1299.

31. Ngo Sock ET, Cote I, Mentor JS, et al. (2013) Ovariectomy stimulates hepatic fat and cholesterol accumulation in highfat diet-fed rats. Horm Metab Res 45, 283-290.

32. Sugioka N, Haraya K, Fukushima K, et al. (2009) Effects of obesity induced by high-fat diet on the pharmacokinetics of nelfinavir, a HIV protease inhibitor, in laboratory rats. Biopharm Drug Dispos 30, 532-541.

33. More VR \& Slitt AL (2011) Alteration of hepatic, but not renal transporter expression in diet-induced obese (Dio) mice. Drug Metab Dispos 39, 992-999.

34. Khemawoot P, Yokogawa K, Shimada T, et al. (2007) Obesity-induced increase of CYP2E1 activity and its effect on disposition kinetics of chlorzoxazone in Zucker rats. Biochem Pharmacol 73, 155-162.

35. WHO (2000) Obesity: Preventing and Managing the Global Epidemic. Report of a WHO Consultation. Geneva: WHO.

36. Statistics CanadaThe Canadian Community Health Survey 2008. http://www.statcan.gc.ca/daily-quotidien/090625/dq0 90625b-eng.htm

37. Buettner R, Scholmerich J \& Bollheimer LC (2007) High-fat diets: modeling the metabolic disorders of human obesity in rodents. Obesity (Silver Spring) 15, 798-808.

38. Moore DD, Kato S, Xie W, et al. (2006) International Union of Pharmacology. LXII. The NR1H and NR1I receptors: constitutive androstane receptor, pregnene $\mathrm{X}$ receptor, farnesoid $\mathrm{X}$ receptor $\alpha$, farnesoid $\mathrm{X}$ receptor $\beta$, liver $\mathrm{X}$ receptor $\alpha$, liver $\mathrm{X}$ receptor $\beta$, and vitamin D receptor. Pharmacol Rev 58, $742-759$.

39. Cote I, Ngo Sock ET, Levy E, et al. (2013) An atherogenic diet decreases liver FXR gene expression and causes severe hepatic steatosis and hepatic cholesterol accumulation: effect of endurance training. Eur J Nutr 52, 1523-1532.

40. Bhathena J, Kulamarva A, Martoni C, et al. (2011) Dietinduced metabolic hamster model of nonalcoholic fatty liver disease. Diabetes Metab Syndr Obes 4, 195-203.

41. Gao J \& Xie W (2091) Pregnane X receptor and constitutive androstane receptor at the crossroads of drug metabolism and energy metabolism. Drug Metab Dispos 38, 5.

42. Finn RD, Henderson CJ, Scott CL, et al. (2009) Unsaturated fatty acid regulation of cytochrome P450 expression via a CAR-dependent pathway. Biochem J 417, 43-54.

43. Hernandez JP, Mota LC \& Baldwin WS (2009) Activation of CAR and PXR by dietary, environmental and occupational chemicals alters drug metabolism, intermediary metabolism, and cell proliferation. Curr Pharmacogenomics Person Med 7, $81-105$.

44. Sonoda J, Chong LW \& Downes M (2005) Pregnane $\mathrm{X}$ receptor prevents hepatorenal toxicity from cholesterol metabolites. Proc Natl Acad Sci US A 102, 2198-2203.

45. Anger GJ \& Piquette-Miller M (2011) Mechanisms of reduced maternal and fetal lopinavir exposure in a rat model of gestational diabetes. Drug Metab Dispos 39, 1850-1859.

46. Nelson DR, Kamataki T, Waxman DJ, et al. (1993) The P450 superfamily: update on new sequences, gene mapping, accession numbers, early trivial names of enzymes, and nomenclature. DNA Cell Biol 12, 1-51.

47. Takagi S, Nakajima M, Mohri T, et al. (2008) Post-transcriptional regulation of human pregnane $\mathrm{X}$ receptor by micro-RNA affects the expression of cytochrome P450 3A4. J Biol Chem 283, 9674-9680. 
48. Klaassen CD \& Aleksunes LMXenobiotic, bile acid, and cholesterol transporters: function and regulation. Pharmacol Rev. 62, 1-96.

49. Jyrki J, Eloranta \& Kullak-Ublick GA (2007) Bile acid transporters. In Drug Transporters: Molecular Characterization and Role in Drug Disposition, [G You and ME Morris, editors]. Hoboken, NJ: John Wiley \& Sons, Inc.

50. Kast HR, Goodwin B, Tarr PT, et al. (2002) Regulation of multidrug resistance-associated protein 2 (ABCC2) by the nuclear receptors pregnane $\mathrm{X}$ receptor, farnesoid $\mathrm{X}$-activated receptor, and constitutive androstane receptor. $J$ Biol Chem 277, 2908-2915.

51. Calkin AC \& Tontonoz P (2012) Transcriptional integration of metabolism by the nuclear sterol-activated receptors LXR and FXR. Nat Rev Mol Cell Biol 13, 213-224.

52. Lefebvre P, Cariou B, Lien F, et al. (2009) Role of bile acids and bile acid receptors in metabolic regulation. Physiol Rev 89, 147-191.

53. Handschin C \& Meyer UA (2005) Regulatory network of lipid-sensing nuclear receptors: roles for CAR, PXR, LXR, and FXR. Arch Biochem Biophys 433, 387-396.

54. Chow EC, Maeng HJ, Liu S, et al. (2009) 1 1 ,25-Dihydroxyvitamin $\mathrm{D}(3)$ triggered vitamin $\mathrm{D}$ receptor and farnesoid
$\mathrm{X}$ receptor-like effects in rat intestine and liver in vivo. Biopharm Drug Dispos 30, 457-475.

55. Chen Y, Tang Y, Guo C, et al. (2012) Nuclear receptors in the multidrug resistance through the regulation of drugmetabolizing enzymes and drug transporters. Biochem Pharmacol 83, 1112-1126.

56. Geick A, Eichelbaum M \& Burk O (2001) Nuclear receptor response elements mediate induction of intestinal MDR1 by rifampin. J Biol Chem 276, 14581-14587.

57. Tirona RG \& Kim RB (2005) Nuclear receptors and drug disposition gene regulation. J Pharm Sci 94, 1169-1186.

58. Maglich JM, Stoltz CM, Goodwin B, et al. (2002) Nuclear pregnane $\mathrm{X}$ receptor and constitutive androstane receptor regulate overlapping but distinct sets of genes involved in xenobiotic detoxification. Mol Pharmacol 62, 638-646.

59. Burk O, Arnold KA, Geick A, et al. (2005) A role for constitutive androstane receptor in the regulation of human intestinal MDR1 expression. Biol Chem 386, 503-513.

60. Yin K, Liao DF \& Tang CKATP-binding membrane cassette transporter A1 (ABCA1): a possible link between inflammation and reverse cholesterol transport. Mol Med. 16, 438-449. 